\title{
Questionnaires: paradigms and pitfalls
}

\author{
Gill Wakley
}

\section{Introduction}

Questionnaires are an inexpensive way to gather data from a potentially large number of people. ${ }^{1}$ Questionnaires can be used in postal or Internet surveys, or as a guide in faceto-face or telephone interviews. Poorly designed questionnaires are a waste of time and effort and are likely to yield meaningless or misleading data; an awareness of the techniques of questionnaire design, application and analysis is essential. Using a questionnaire is a multistage process, so carry out every step carefully. Questionnaires may be cheap to administer compared with other data collection methods, but they take just as long to design, interpret and write up the results. You might look at the process as a flow chart (Box 1).

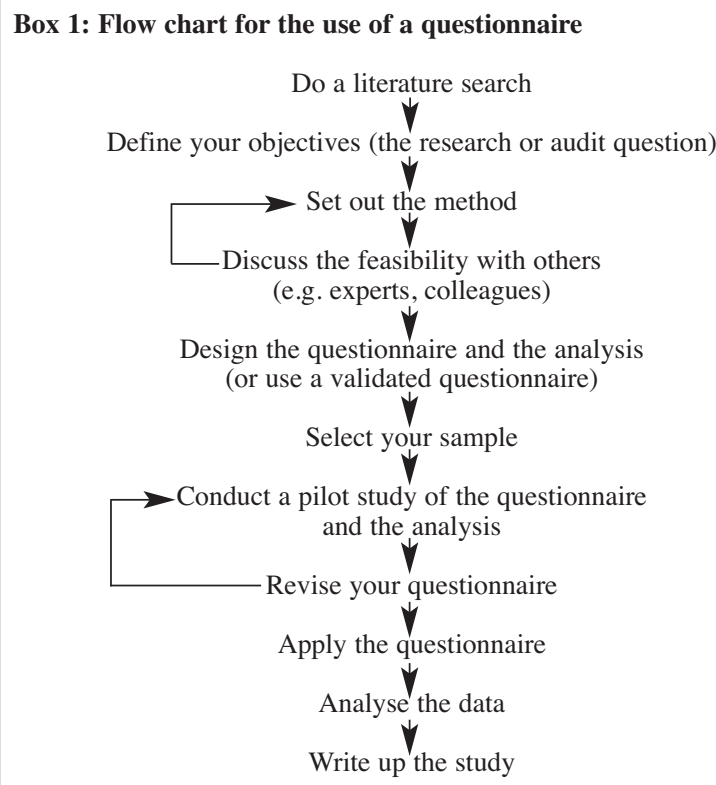

\section{Advantages of questionnaires}

- Familiarity: As most people have previous experience of completing a questionnaire, anxiety is reduced for respondents with competent reading skills. Face-to-face interview situations are also common and, provided the interviewer is competent, people are comfortable with the technique.

- Cost effective: Most research or audit methods have similar set-up costs but questionnaires are a costeffective instrument of data collection, especially for large sample sizes or large geographical areas.

- Ease of analysis: Data entry and tabulation can usually be done with a software package, provided you design this at the same time as the questionnaire.

- Reduction of bias: The questions in a postal or Internet survey are presented in a uniform manner with no influence from an interviewer or observer. Training of interviewers for one-to-one surveys reduces bias introduced by the interviewer.

J Fam Plann Reprod Health Care 2005; 31(3): 222-224

Staffordshire University, Stafford, UK

Gill Wakley, MD, MFFP, Visiting Professor in Primary Care

Development and Freelance General Practitioner

Correspondence to: Professor Gill Wakley.

E-mail: gillwak@aol.com
- Lack of intrusiveness: Unlike telephone or face-toface interviews, a respondent can complete a postal or Internet questionnaire at a time of his or her own choosing. You can invite respondents to choose a convenient interview time to increase response rates

\section{Disadvantages of questionnaires}

- Low response rates: Response rates vary widely and a low response rate will not give reliable information on which to base conclusions. Response rates are reduced by poor design and a large number of questions, or if the respondents receive frequent requests for completion of questionnaires. Poor completion rates are also likely if the questionnaire takes too long to answer.

- Loss of flexibility: Respondents often want to qualify answers in a questionnaire. Space for comments is useful, but too much space for free comment makes the questionnaire time consuming to code and analyse. Balance easy to quantify closed questions with identifying important information from openended questions. Face-to-face or telephone application provides more flexibility but introduces more bias.

- Lack of information about attitudes: Tick boxes are a good way of obtaining data about facts but attitudes are probably better explored in face-to-face interviews (or focus groups), where non-verbal information and discussion can tease out hidden values.

- Identity confounding: You might assume that the questionnaire has been completed by the person to whom it was sent, but they may have moved, or someone else (e.g. a secretary or a partner) may have completed it on his or her behalf. Face-to-face and telephone interviews usually avoid this confounding issue, but postal and Internet surveys are particularly vulnerable.

- Unsuitability for the target sample: The subject matter may be perceived as irrelevant, or as something that cannot be altered, particularly if previous feedback has been ignored - so expressing an opinion is not worthwhile. People with poor literacy skills are unlikely to complete written questionnaires. You would not want to target unemployed homeless people with an Internet survey!

\section{Define your objectives}

This is the most important part! Your literature search may show that the area in which you are interested has masses of data already and a review article is more appropriate than further research.

If you have well defined, precise objectives then the questions flow naturally from them. If there is little literature on the subject then you may need to use other methods, such as a focus group, to determine the right questions to ask a wider group of people.

Consider how you will use the information gained. Who is the intended target for the information? You would include different questions if your aim is to persuade management to fund a new service from those used where you wish to feedback to the staff how well they are providing an existing service. 


\section{Designing the questionnaire}

Use a validated questionnaire that has already been well tested if possible. It saves time and you will be able to compare your results with others. You might want to use a previously published questionnaire with just a few supplementary questions for your own specific purposes. Using a previously published validated questionnaire increases the reliability and the validity of your survey (Box 2).

If you have to design your own questionnaire, consult the extensive literature on questionnaire design. ${ }^{2-7}$ Important facets to consider are:

- Length: Keep it short. Go through it again and again, eliminating questions. Long questionnaires reduce the response rate and a low response rate means you have wasted your time. Use only the questions that will affect a decision or provoke change.

- Include the analysis at the planning stage: If you cannot specify how you will analyse the question, do you need that question?

- Make it noticeable: If the envelope and questionnaire of a postal survey stand out from all the rest of the paper people receive it is more likely to be completed. 8 An Internet survey may be notified with a pop-up box attached to an e-mail, or trailed on a frequently visited page.

- Make it easy to return: Include a stamped addressed envelope and also a return address on a postal questionnaire so that it can still be returned if the envelope is lost. A single click at the end of an Internet survey should send it off.

- Include a convincing cover explanation: This is your chance to persuade someone to complete the questionnaire. Response rates are increased by personal

\begin{tabular}{|ll|}
\hline Box 2: Validity and reliability \\
$\begin{array}{l}\text { Validity } \\
\text { ('The answers } \\
\text { obtained are } \\
\text { true') }\end{array}$ & $\begin{array}{l}\text { If you ask health professionals whether they 'ask } \\
\text { about a family history of venous thrombosis before } \\
\text { prescribing the combined oral contraceptive' you } \\
\text { may elicit the answer 'Yes' or 'Almost always'. }\end{array}$ \\
& $\begin{array}{l}\text { What health professionals say, or think, that they } \\
\text { do may not be what they do in practice (i.e. the } \\
\text { answer may not be true). }\end{array}$ \\
& $\begin{array}{l}\text { Asking patients if they were asked about } \\
\text { thrombosis may elicit the answer 'No' or 'Don't }\end{array}$ \\
know' because of recall difficulties (i.e. the answer \\
may not be true).
\end{tabular}

contact from someone the respondent knows or respects.

- Give clear instructions: Use short sentences and simple words. Ask other people for early feedback: what you meant may not be what is understood by others. Your pilot study will help to establish if you have made the instructions clear.

- Include interesting but non-threatening questions at the beginning: Opinion is divided about whether demographic data such as name and address, date of birth, and so on, should be at the beginning or the end. If the questions are sensitive or embarrassing, you may need anonymous completion; but if they are not, people may prefer to complete the questionnaire first before revealing who they are. ${ }^{9}$

- Provide incentives: If the results will be of interest to the respondent, offer them a copy of the results. Think about monetary incentives, or shop or book tokens, all of which increase the response rate. ${ }^{10-12}$

- Professional production: Take advice on setting out a written questionnaire so that it is easy to read and looks attractive. The font size of the print should be easy to read with plenty of space around the questions to avoid confusion. Progression from one section to another should be easy to follow and execute.

- Unambiguous wording of the questions: Box 3 includes some of the common pitfalls, but expert advice and your pilot study (or repeated pilot studies if you get it very wrong first time) will help you to avoid confusion.

- Open or closed questions: If you use open-ended questions, plan for how they will be coded and analysed. Giving examples of how you would prefer the answer to be worded can make this easier, but restricts the freedom of response. You may need to ask for help from a researcher trained in qualitative methods if you have little experience in this field. ${ }^{13}$ Closed questions can cause frustration, particularly if the researcher has not thought of all the possible responses, so adding space for comments increases completion rates and provides new insights for the researcher.

\section{Comparison of application methods}

Face-to-face administration of the questionnaire in the presence of the respondents gives an opportunity to explain the questions, the response rate is usually higher (especially for full completion of all the questions), and probing on answers can obtain further information to augment the replies. Pressure on the participants to give an answer may lead to biased or false information being given. The interviewers may be inconsistent in applying the questionnaire, perhaps altering the questions to fit the respondent's perceived understanding or likely response, or omitting questions because of pressure of time or perceptions of irrelevance to that respondent. Training, and preferably role-play rehearsal, in the application of the questionnaire helps to avoid these confounding issues.

Telephone interviews have much the same advantages and disadvantages as face-to-face interviewing. It may be easier to obtain a wider spread of respondents, but guard against selection bias. A convenience sample may exclude people who are working or from disadvantaged groups.

Postal surveys are inexpensive and can cover large geographical areas or sociological groups. The respondents can reply in their own time but it is difficult to be sure that the questions have been understood or answered correctly. Low return rates often cause problems with the interpretation.

Internet surveys have relatively little research material for comparison. ${ }^{14}$ Data can be collected by electronic one- 


\section{METHODOLOGY}

\begin{tabular}{|c|c|}
\hline \multicolumn{2}{|c|}{ Box 3: Writing good questions } \\
\hline Produces a true answer & $\begin{array}{l}\text { Increase the confidence of the respondents by } \\
\text { stating your policy on the confidentiality of } \\
\text { the answers. }\end{array}$ \\
\hline $\begin{array}{l}\text { Asks for an answer on } \\
\text { one dimension }\end{array}$ & $\begin{array}{l}\text { Never ask two questions in one (e.g. Were } \\
\text { you satisfied with the access and welcome at } \\
\text { the clinic?). Respondents may be happy with } \\
\text { the welcome but not the access: if this is the } \\
\text { case, how do they answer? }\end{array}$ \\
\hline $\begin{array}{l}\text { Can accommodate all } \\
\text { the possible answers }\end{array}$ & $\begin{array}{l}\text { A question: Who did you see in the clinic? } \\
\text { A. The nurse } \\
\text { B. The doctor } \\
\text { does not include, 'Both', 'Any other staff' or } \\
\text { a 'Don't know' answer. }\end{array}$ \\
\hline $\begin{array}{l}\text { The answers produce } \\
\text { no ambiguity in the } \\
\text { reader's mind }\end{array}$ & $\begin{array}{l}\text { A question: How did you travel to the clinic? } \\
\text { A. Car } \\
\text { B. Bus } \\
\text { C. Bicycle } \\
\text { D. Train } \\
\text { E. Walked } \\
\text { may be difficult to answer if the respondent } \\
\text { had to combine methods of transport. } \\
\text { Similarly, when asking questions about } \\
\text { frequency have clearer options than 'Very } \\
\text { often' to 'Seldom' (which mean different } \\
\text { things to people) such as specifying time } \\
\text { intervals such 'Every day' or 'Once a year'. }\end{array}$ \\
\hline $\begin{array}{l}\text { Produces variable } \\
\text { responses }\end{array}$ & $\begin{array}{l}\text { A question: Did you find the reception you } \\
\text { received was: } \\
\text { A. Welcoming? } \\
\text { B. Neither welcoming or } \\
\text { offputting? } \\
\text { C. Off-putting? } \\
\text { Most people would answer B. A wider scale } \\
\text { would draw out more variability in response. }\end{array}$ \\
\hline $\begin{array}{l}\text { The questions flow } \\
\text { comfortably from one } \\
\text { to another }\end{array}$ & Group questions on similar subjects together. \\
\hline $\begin{array}{l}\text { Does not make prior } \\
\text { assumptions }\end{array}$ & $\begin{array}{l}\text { A question: Are you satisfied with your } \\
\text { method of contraception? Yes/No } \\
\text { assumes the respondent uses contraception. } \\
\text { Include options to state that the respondent is } \\
\text { not using contraception currently. }\end{array}$ \\
\hline $\begin{array}{l}\text { Does not imply the } \\
\text { answer }\end{array}$ & $\begin{array}{l}\text { A question: You wouldn't like to pay for } \\
\text { contraceptive prescriptions, would you? } \\
\text { predicts a fairly obvious answer, so is not } \\
\text { worth asking. }\end{array}$ \\
\hline
\end{tabular}

to-one interviews by e-mail or using a chat room or forum. Questionnaires can be completed on e-mail, attachments or fill-in forms on a web page. The selection of the sample is particularly important, as Internet users may not be representative and may be self-selected. Electronic respondents tend to be better educated and have higher incomes. You will need a mechanism to prevent repeated completion by the same person. You may also wish to select certain groups by screening questions at the start that then prevent others from completing the rest of the questions. The data collected is readily analysed.

\section{Avoidance of bias}

Consult the literature on the nature of bias and confounding in research and audit studies. ${ }^{15-17}$ Pitfalls to avoid include:

- Incorrect selection of the sample so that it not representative (e.g. only asking people who attended a clinic if it was conveniently situated). If your sample is not representative, you will not be able to generalise the findings to other populations. This will not matter if you only want to audit your local users, but is important if you want to convince administrators of your case for new services for non-users of your services.
- Having a large proportion of non-responders runs the danger that their responses may have been different from those who did respond, or that they differ in their characteristics from those that responded.

- Avoid asking about matters that rely on memory or your study will suffer from recall bias. Particularly good or dreadfully bad experiences are preferentially remembered!

- Assuming the effects of your intervention are responsible for changes recorded without establishing what other interventions were occurring (e.g. if knowledge about chlamydia increased after an information campaign in your practice is it due to that, or following an article in a popular women's magazine?).

\section{Summary}

Always use a questionnaire for a carefully thought out purpose, not just to collect data and then think what to do with it. Plan your analysis as part of the design process. Keep in mind the target audience for the information you collect and how the conclusions will be presented. Use an already validated questionnaire if you can. If none exists, you will need to seek expert advice, pilot the instrument (sometimes several times), and ensure that sources of bias and confounding are avoided as far as possible. Make your invitation to participate in completing the questionnaire stand out and make the process as short and easy to complete as possible. Good luck with your response rates!

Statements on funding and competing interests

Funding. None identified.

Competing interests. None identified.

References

1 O'Toole BI, Battistutta D, Long A, Crouch K. A comparison of costs and data quality of three health survey methods: mail, telephone and personal home interview. Am J Epidemiol 1986; 124: 317-328.

2 Sapsford R. Survey Research. London, UK: Sage Publications, 1999.

3 Boynton PM, Greenhalgh T. Selecting, designing, and developing your questionnaire $B M J$ 2004; 328: 1312-1315.

4 Furnham A, Jackson C. Designing and Analysing Questionnaires and Surveys. A Manual for Health Professionals and Administrators. London, UK: Whurr Publishers, 1999.

5 http://www.accesscable.net/ infopoll/tips.htm.

6 McColl E, Thomas R. The Use and Design of Questionnaires. London, UK: Royal College of General Practitioners, 2000.

7 Polgar S, Thomas SA. Introduction to Research in the Health Sciences. Melbourne, Australia: Churchill Livingstone, 1991.

8 Kaner EFS, Haighton CA, McAvoy B. 'So much post, so busy with practice - so, no time!': a telephone survey of general practitioners' reasons for not participating in postal questionnaire surveys. Br J Gen Pract 1998: 48: 1067-1069.

9 Lee RL. Doing Research on Sensitive Topics. London, UK: Sage Publications, 1993

10 Edwards P, Roberts I, Clarke M, DiGuiseppi C, Pratap S, Wentz R, et al. Increasing response rates to postal questionnaires: systematic review. BMJ, 2002; 324: 1183 .

11 Moses SH, Clake TJ. Effect of a prize draw on the response rate to a postal survey of obstetricians and gynaecologists. A randomised controlled trial. BMC Health Serv Res 2004, 4: 14.

12 Barclay S, Todd C, Finlay I, Grande G, Wyatt P. Not another questionnaire! Maximizing the response rate, predicting non-response and assessing non-response bias in postal questionnaire studies of GPs. Fam Pract 2002; 19: 105-111.

13 Moser CA, Kalton G. Survey Methods in Social Investigation. Aldershot, UK: Dartmouth Publishing Company, 1992.

14 Eysenbach G, Wyatt J. Using the Internet for surveys and health research. J Med Internet Res 2002; 4: e13. http://www.jmir.org/ 2002/2/e13/

15 Davey Smith G, Ebrahim S. Data dredging, bias, or confounding. BMJ 2002; 325: 1437-1438.

16 Rhodes AE, Lin E, Streiner DL. Confronting the confounders. The meaning, detection and treatment of confounders in research. Can J Psychiatry 1999; 44: 175-179.

17 Clarke R, Croft P. Critical Reading for the Reflective Practitioner Oxford, UK: Butterworth Heinemann, 1998. 